\title{
Health care reform: The ball's in the voter's court
}

$\mathrm{F}$ ed up with "glaring failures of vision and leadership" for health reform at all levels of government, patients and health care professionals at the Canadian Medical Association's third town hall on health care transformation called for a "social movement" to "hold politicians' feet to the fire" in the run up to the May 2 federal election.

Canadians must take collective and individual responsibility for the country's health care crisis if they are to achieve meaningful and systemic reforms, participants to the session in Edmonton, Alberta, argued.

While Canadians have consistently ranked health care as their top priority, the nation's political leaders have been disappointingly silent on the subject of health reform, said Dan MacLennan, panelist and former president of the Alberta Union of Provincial Employees. "You don't hear it discussed. I wouldn't even care if a coalition [government] came up with a solution at this point. It's embarrassing, the level of debate."

Although federal politicians often dodge health issues by asserting that health is a provincial jurisdiction, the federal government could and should play a critical role in reshaping Canada's health care system by attaching national standards and accountability measures to health transfer payments it makes to the provinces, said Dr. Jeff Turnbull, panelist and president of the Canadian Medical Association. "We should expect an awful lot from the federal government because the contribution it provides is significant. It should be greater, but they still could be setting out expectations to facilitate the delivery of care in each and every province across Canada."

"We want to know you get approximately the same health care whether you're in Calgary or Cape Breton," he added. "That's what the federal government is there for - they're the custodians of the Canada Health Act and they should be protecting it."

Canadians must press politicians

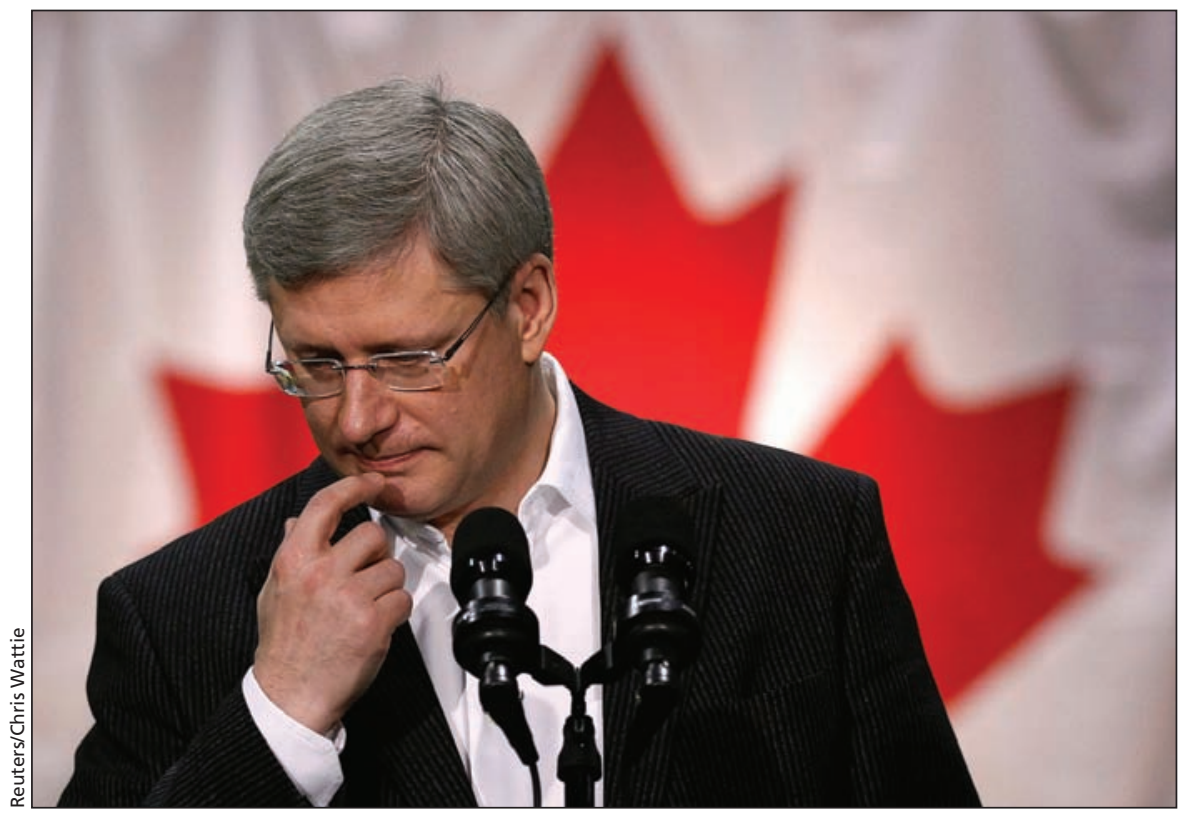

Canadians must press politicians into action rather than wait for them to lead change, argued panelists at the Canadian Medical Association's third town hall meeting on health care transformation.

into action rather than wait for them to lead change, argued Dr. Patrick White, panelist and president of the Alberta Medical Association. "You get the politicians you deserve. The electoral system is geared so we just keep getting the same old dirty shirts all the time, and to go outside that, we need a social movement. When you think about national debates around HIV, sexual orientation or smoking, what made the difference? It wasn't politicians making decisions."

Canadians have an individual and collective responsibility to advocate for the health care they want, said MacLennan. "Some $95 \%$ of federal candidates who were MPs [Members of Parliament] are running again, and there's a real strong likelihood we'll elect those same people we're complaining about now and continue to complain about them for the rest of May and into the future."

For all the frustrations Canadians experience interacting with the health care system, they're not translating their anger into political action, said
White. "You have to talk to your MP and say you're not satisfied with the vision they're providing for our health care system. You have to go to the people who make decisions and say this is the way it should be."

Part of the problem is that many people "don't realize how limited the Canada Health Act is," said Noel Somerville, chair of Public Interest Alberta's Seniors' Task Force. "Medically necessary services are not covered [such as] pharmacare, long term care and home care."

Apathy and a sense that "the system's broken and we can't fix it" have also slowed reform, said Turnbull. "But we can fix it. It can be done."

Fixing the system will require Canadians to not only advocate for change, but live it as well, said Rachel Bard, panelist and CEO of the Canadian Nurses Association. "Canadians need to look at their lifestyles [and] ask what they can do to sustain the system we have right now."

Keeping doctors' appointments, following treatment plans, eating healthy 
and not expecting "a pill for every ill" were among measures that participants said Canadians could take to reduce strain on the health care system.

"That's where personal responsibility starts," said Cathy Gulli, panelist and Maclean's associate editor. "It also starts with being honest with our doctors. A lot of us are intimidated and anxious about speaking honestly with our physician about what's going on in our life that's affecting our health."

However, personal responsibility can be a "sticky issue for patients and doctors to negotiate, because it can ebb into blame territory," she cautioned. "Clearly the lifestyle choices we make have a direct impact on our health. In some cases, we've taken our health for granted and in others. it's because we can't afford better food, a gym membership or the support systems necessary to break bad habits and addictions. The sad reality is even if we did everything right many of us will find ourselves inside our doctor's office getting terrible news." - Lauren Vogel, CMAJ

CMAJ 2011. DOI:10.1503/cmaj.109-3857 